\title{
Meningeal Irritation Due to Tetracycline Administration
}

\author{
S. G. F. WILSON and W. J. DALLY \\ From the Dundee Royal Infirmary, and Fyfe-Jamieson Maternity Home, Forfar
}

Side-effects of therapy with the tetracycline group of antibiotics are well known (Pflug, 1963). They include nausea and vomiting, diarrhoea due to superinfection with Candida albicans or resistant staphylococci, skin rashes, photosensitivity (most commonly following demethylchlortetracycline), increase of blood urea, and fatty degeneration of the liver. In addition, certain side-effects are peculiar to the newborn baby and infant. Cohlan, Bevelander, and Tiamsic (1963) reported a $40 \%$ inhibition of normal skeletal growth of the premature infant during tetracycline administration, the inhibition ceasing after treatment was stopped. Yellow pigmentation of the primary dentition following treatment, especially with tetracycline, is relatively common (Milch, Rall, and Tobie, 1958; Hilton, 1962; Davies, Little, and Aherne, 1962; Wallman and Hilton, 1962). Less well known is the occasional occurrence of a bulging fontanelle in an otherwise healthy infant receiving tetracycline (Gellis, 1956; Millichap, 1959; Fields, 1961). This alarming sign is apparently benign and quickly disappears on stopping treatment, but its occurrence usually calls for rapid exclusion of more serious causes. The following case is thought to be an example of this complication.

\section{Case Report}

The patient, a 3-day-old female infant, was her mother's third child. She was delivered normally at term and no resuscitation was required. The birth weight was $2955 \mathrm{~g}$. The liquor was noted to be scanty, green, and offensive. A swab from the foetal surface of the placenta grew a Staphylococcus pyogenes, which was sensitive to cloxacillin, fucidin, and erythromycin, partly sensitive to tetracycline, and resistant to penicillin and sulphafurazole. From birth, and before bacterial sensitivities were known, the infant was given $25 \mathrm{mg}$. tetracycline ( 5 drops of 'achromycin' paediatric drops) every 4 hours as a prophylactic measure, i.e. $50 \mathrm{mg}$. $/ \mathrm{kg}$. day. On the third day she was noted to have a bulging fontanelle, head retraction, and an arched back. There

Received February 24, 1966. was slight cyanosis of the lips and hands. She had been feeding well, and in other respects her progress was normal. There were no convulsions. 14 doses of tetracycline had been given, i.e. a total of $350 \mathrm{mg}$.

On admission her temperature was $36 \cdot 3^{\circ} \mathrm{C}$., weight $2910 \mathrm{~g}$. The anterior fontanelle was bulging but soft, the head retracted, and the back arched. The child did not look seriously ill. The Moro reflex, walking reflex, and grip reflex were all present. The pupils were equal and reacted to light, and the fundi were normal. There was no dyspnoea, and there were no abnormal signs in the chest or abdomen. Two attempts at both lumbar puncture and lateral ventricular tap were unsuccessful, but approximately $1 \mathrm{ml}$. CSF was obtained from the subarachnoid space when subdural taps were performed. No subdural haemorrhage was present. The fluid contained 8000 red blood cells/c.mm., 4 lymphocytes/ c.mm. and $62 \mathrm{mg}$. protein $/ 100 \mathrm{ml}$. There was insufficient for estimation of sugar content. No organisms were grown. A chest radiograph showed bilateral, patchy opacities in both lower lobes.

Tetracycline was stopped on admission, and replaced by intramuscular streptomycin $75 \mathrm{mg}$. b.d. and intramuscular cloxacillin, $125 \mathrm{mg}$. 6-hourly. By 18 hours after admission there was no bulging of the anterior fontanelle, no head retraction, and no arching of the back. She behaved normally in all respects, fed well, and began to gain weight. Antibiotic treatment was stopped on the seventh hospital day when a chest radiograph was normal. She went home on the eighth day. At follow-up at the age of 6 months she was making normal physical and mental progress.

\section{Discussion}

The history and signs on admission were very suggestive of meningitis. The inability to obtain cerebrospinal fluid either by lumbar puncture or by ventricular tap made the exclusion of meningitis less than certain. However, the absence of a leucocytic reaction in the fluid obtained from the subarachnoid space, its bacteriological sterility, and the rapid disappearance of the signs of meningeal irritation, and increased intracranial tension made it unlikely that this serious neonatal infection was present. Subdural and cerebral haemorrhage were thought unlikely by finding no blood in the subdural space, 
and by the absence of neurological signs such as convulsions, suppression of normal reflexes, excessive irritability, and coarse limb tremor. The subsequent normal physical and mental progress of the infant also made cerebral damage unlikely.

A third possible cause for the signs was meningismus associated with the pulmonary infection. This infection was not an important feature of the illness, and the signs amounted only to minimal radiological changes at the bases. It is probable that it was due to the aspiration of infected material at delivery, and it appeared to be resolving by the time the bulging fontanelle was observed.

Less common causes of increased intracranial tension (Millichap, 1959) could be excluded with certainty. She did not have otitis media; vitamin A had not been given either to the baby or to the mother in large doses, nor did either show signs of hypovitaminosis $A$; she did not have radiological changes of hypophosphatasia; and steroids had not been given either to mother or baby.

As none of the obvious causes of increased intracranial tension was present, and tetracycline is known to cause a bulging fontanelle, it was thought probable that this was an example of a reaction to the antibiotic. Neck stiffness and arching of the back have not previously been recorded following the administration of tetracycline, but there is no reason to believe it could not occur if it is accepted that tetracycline may cause a bulging fontanelle. The time relationship of stopping tetracycline therapy and the disappearance of the dramatic physical signs and complete return of the baby to normality was a very close one, and the conclusion was that tetracycline was responsible for the clinical picture.

The pathogenesis is uncertain but is probably due to a combination of factors. Sereni, Perletti, Manfredi, and Marini (1965) were able to show that an analogue of tetracycline, namely tetracycline-1methylene-lysine (lymecycline) is excreted more slowly by the human newborn baby than by an older infant, probably because of the lower glomerular filtration rate of early life. The plasma concentrations 6 and 12 hours after the administration of a single oral dose of $12 \mathrm{mg}$. $/ \mathrm{kg}$. of the tetracycline analogue to babies were always significantly higher than those after similar doses administered to infants over 2 months old. The same paper reported that the brain tissue concentration of the tetracycline analogue in newborn rabbits was approximately 10 times higher than that in 60-dayold rabbits, given the same dose weight for weight. Among the tissues examined only the brain showed a marked accumulation of analogue in the newborn compared with the older animal. Similar results would probably be found with tetracycline.

It can be assumed that the relatively high doses of tetracycline given to the infant under discussion produced a high plasma tetracycline concentration, and that, if the brain of the human newborn infant also shows preferential concentration of tetracycline, the cerebral signs observed might have been those of a local reaction to an unusually high brain tissue concentration of tetracycline. Further evidence is needed to show whether or not human neonatal brain tissue has as high an affinity for tetracycline as the neonatal rabbit's brain has for the tetracycline analogue.

\section{Summary}

An infant, whose mother's liquor was scanty, offensive, and infected, was given tetracycline prophylactically from birth. At the age of 3 days she had a soft bulging anterior fontanelle, head retraction, and arching of the back. This was thought to be due to treatment with tetracycline, rather than meningitis, birth trauma, or other known causes.

The authors are grateful to Dr. L. B. Hunt, of Lederle Laboratories, for help in preparing this report.

\section{REFERENCES}

Cohlan, S. Q., Bevelander, G., and Tiamsic, T. (1963). Growth inhibition of prematures receiving tetracycline. Amer. F. Dis. Child., 105, 453.

Davies, P. A., Little, K., and Aherne, W. (1962). Tetracyclines and yellow teeth. Lancet, 1, 743.

Fields, J. P. (1961). Bulging fontanel : a complication of tetracycline therapy in infants. F. Pediat., 58, 74.

Gellis, S. S. (1956). Editorial comment. In The Year Book of Pediatrics, 1956-1957 Series, p. 40. Year Book Publishers, Chicago.

Hilton, H. B. (1962). Skeletal pigmentation due to tetracycline. f. clin. Path., 15, 112.

Milch, R. A., Rall, D. P., and Tobie, J. E. (1958). Fluorescence of tetracycline antibiotics in bone. $\mathcal{F}$. Bone $\mathcal{f t}$ Surg., 40A, 897.

Millichap, J. G. (1959). Benign intracranial hypertension and otitic hydrocephalus. Pediatrics, 23, 257.

Pflug, G. R. (1963). Toxicities associated with tetracycline therapy. Amer. F. Pharm., 135, 438.

Sereni, F., Perletti, L., Manfredi, N., and Marini, A. (1965), Tissue distribution and urinary excretion of a tetracycline derivative in newborn and older infants. F. Pediat., 67, 299.

Wallman, I. S., and Hilton, H. B. (1962). Teeth pigmented by tetracycline. Lancet, 1, 827. 